\title{
ESTUDO DA RESISTÊNCIA À CORROSÃO DO AÇO INOXIDÁVEL AISI 304 EM ÁGUA DO MAR NATURAL E ARTIFICIAL*
}

\author{
Etiene Pereira de Andrade ${ }^{1}$ \\ Carolina Martins Abreu² \\ Maria Teresa Paulino Aguilar ${ }^{3}$ \\ Wellington Lopes ${ }^{4}$
}

\section{Resumo}

Este trabalho avaliou a influência da deformação na formação de martensita e consequente resistência à corrosão do aço inoxidável austenítico AISI 304. O aço foi deformado em cisalhamento de $10 \%, 25 \%, 30 \%, 50 \%$ e $55 \%$ de deformação efetiva e em seguida mergulhado em solução contendo água do mar natural e artificial. As amostras imersas em solução de água do mar artificial exibiram aumento da massa enquanto as mergulhadas em água natural, redução. Esses resultados podem ser associados com a aderência inicial e estável de íons metálicos advindos dos cloretos, à superfície do material mergulhado em água do mar artificial.

Palavras-chave: Corrosão; Atmosfera marinha; Aço inoxidável AISI 304; Martensita.

\section{STUDY OF THE CORROSION RESISTANCE OF STAINLESS STEEL AISI 304 IN NATURAL AND ARTIFICIAL SEA WATER}

\begin{abstract}
This work evaluated the influence of deformation on the formation of martensite and consequent corrosion resistance of austenitic stainless steel AISI 304. This steel was pre-strained by shearing tests up to $10 \%, 25 \%, 30 \%, 50 \%$ and $55 \%$ of effective strain and immersed in natural and artificial sea water. The samples immersed in artificial sea water exhibited increased mass while immersed in natural water reduction. These results can be associated with the initial adhesion of the metal ions arising from chlorides, the surface of the material immersed in artificial seawater.
\end{abstract}

Keywords: Corrosion; Marine atmosphere; Stainless steel AISI 304; Martensite.

1 Engenharia de Materiais, Centro Federal de Educação Tecnológica de Minas Gerais, Belo Horizonte, MG, Brasil. andrade.etiene@hotmail.com

2 Engenharia Mecânica, Universidade Federal de Minas Gerais, Belo Horizonte, MG, Brasil. abreu.carolinabr@gmail.com

3 Engenharia de Materiais e Construção Civil, Universidade Federal de Minas Gerais, Belo Horizonte, MG, Brasil.teresa@ufmg.br

4 Engenharia de Materiais, Dr., Prof., Departamento de Engenharia de Materiais, Centro Federal de Educação Tecnológica de Minas Gerais (CEFET-MG), Belo Horizonte, MG, Brasil. wellingtonlopes@deii.cefetmg.br. 


\section{INTRODUÇÃO}

De modo geral, corrosão é a deterioração de materiais por ação química ou eletroquímica do meio ambiente. O meio no qual o material está interfere drasticamente em seu processo corrosivo, mas quando associado a solicitações mecânicas a deterioração torna-se ainda mais acelerada [1].

Um dos materiais que encontram boa conformabilidade e elevada resistência à corrosão são os aços inoxidáveis austeníticos. Contudo apresentam estrutura austenítica à temperatura ambiente (metaestáveis), por serem passíveis de sofrer transformação de fases induzida por deformação, originando martensita (seja ela $\alpha^{\prime}$, cúbica de corpo centrado - CCC ou $\varepsilon$, hexagonal compacta - HC). A formação de martensita, em alguns casos, pode ser responsável por acelerar o processo corrosivo.

O objetivo deste trabalho é avaliar o efeito dessas transformações de fases induzidas por deformação plástica no aço inoxidável austenítico AISI 304. Trabalhou-se sob diferentes modos, quantidades e taxas de deformação efetiva. Foram então correlacionados os respectivos aspectos mecânicos e estruturais decorrentes das condições de solicitação mecânica à resistência à corrosão desse material em diferentes meios: água do mar natural e artificial.

\subsection{Aços inoxidáveis e a corrosão}

A corrosão de materiais previamente deforma pode envolver duas etapas: nucleação e propagação da trinca. A propagação caracteriza-se por um tempo mínimo de indução, associado à formação de pites ou à emergência de discordâncias sucessivas na superfície do metal [1].

Quando o meio contém uma concentração de íons cloretos $\left(\mathrm{Cl}^{-}\right)$menor do que 2 $\mathrm{mol} / \mathrm{L}$, observa-se apenas a formação de pites; porém quando a concentração é aumentada, nota-se a presença de vestígios de corrosão transgranular e a morfologia dos sítios corroídos se altera, agravando-se à medida que a quantidade de íons $\mathrm{Cl}^{-}$aumenta. A fratura transgranular de aços austeníticos em meios que contém tal agente é bastante frequente [1,2]

Esse tipo de corrosão manifesta-se, nos aços inoxidáveis, principalmente em soluções ou meios que contenha elevada concentração de íons cloreto ou sais ácidos (os quais diminuem o pH do meio, acelerando a cinética de propagação e formação dos pites). Dessa forma, uma das atmosferas mais agressivas a esses aços é a marinha, a qual também contém outro agente potencializador; a presença de microrganismos.

Pode-se dizer que a ação corrosiva da água do mar pode ser determinada, ao menos inicialmente, por sua salinidade, a qual (salvo exceções) é aproximadamente constante, em torno de 3,5\%. Claro, a quantidade de sais dissolvidos, bem como sua variedade, difere de acordo com a região analisada, mas tem-se um perfil padrão, conforme norma ASTM D1141/98 [3].

Apesar disso, trata-se o mar de um meio complexo constituído de sais, matéria orgânica (viva e em decomposição), gases dissolvidos e uma diversidade de outros compostos e substâncias que também podem potencializar os efeitos corrosivos desse meio. Assim, apesar da norma e da padronização, observações e testes experimentais em água do mar artificial não são capazes de reproduzir fielmente a realidade $[1,3]$. 


\subsection{Influência da formação de martensita na resistência à corrosão}

A martensita formada por deformação nos aços inoxidáveis austeníticos pode interferir na cinética de formação da película passivadora dos mesmos, podendo agravar a ação corrosiva do meio externo. Peguet, Malki e Baroux [5] associam a diminuição da resistência à corrosão não à formação de martensita por deformação, mas à formação de bandas de cisalhamento e à modificação da densidade de discordâncias do material. Sendo que tal fenômeno é, em parte, reafirmado por Jinlong, Hongyun [6], que dizem que as bandas de cisalhamento, tal qual afirmado por Padilha, Guedes [7], são determinantes no percentual de martensita formado.

A interferência da formação de martensita por deformação na resistência à corrosão deve-se ao fato da mesma modificar a condutividade, microestrutura, composição e capacitância dos filmes passivadores, bem como a quantidade e propagação de áreas anódicas e catódicas, as quais determinam o número e extensão dos pites $[1,6]$.

O aumento da deformação também pode ser associado à "destruição" do filme passivador, com aumento da densidade de áreas anódicas e catódicas, fazendo com que a resistência à corrosão diminua [1,8]. Sabe-se que a formação de martensita (seja $\varepsilon$ ou $\alpha^{\prime}$, sendo esta predominante àquela) afeta a estrutura do filme passivador, devido ao aumento da densidade de discordâncias e planos de maclação. Pode-se estabelecer uma relação quase linear entre o aumento do teor de martensita e a diminuição da resistência à corrosão [8]

Porém, Peguet, Malki e Baroux [5] dizem que a quantidade de martensita formada por deformação em nada ou quase nada interfere na dinâmica dos filmes de óxidos de cromo de aços inoxidáveis, não influenciando na corrosão dos mesmos [5]. Dessa forma, as relações supracitadas são complexas e serão objeto de estudo do presente trabalho.

\section{MATERIAL}

Neste trabalho foram utilizadas chapas de aço inoxidável austenítico AISI 304, no estado como recebido (laminado a frio) cuja composição química (\% em peso) foi de 0,035C, 1,025Mn, 0,356Si, 0,038P, 0,001S, 18,090Cr, 8,038Ni e 0,038Mo.

\section{MÉTODOS}

A caracterização mecânica inicial foi feita com a medição por meio do ensaio de microdureza Vickers com uso do microdurômetro Vickers Shimadzu ${ }^{\circledR}$ HMV - 2T, mediante a escolha correta da carga de indentação, de cerca de $200 \mathrm{gf}$, aplicada durante 15 segundos sobre a superfície do material lixado em 12 pontos de uma mesma amostra. O ensaio de dureza foi feito no aço AISI 304 no estado como recebido e sem qualquer preparação prévia e após as operações de lixamento.

O aço AISI 304 no estado como recebido foi ensaiado com uso da técnica de cisalhamento planar simples utilizando dispositivo acoplado à máquina de ensaios universais Instron ${ }^{\circledR} 5582$ e corpos de prova com dimensões de aproximadamente 50 $\mathrm{mm} \times 15 \mathrm{~mm} \times 0,50 \mathrm{~mm}$ (comprimento $\times$ largura $\times$ espessura) [9].

O ensaio de cisalhamento foi utilizado por ser esta uma das formas de deformação empregada aos mais diversos materiais que passam por transformação mecânica em algum processo de conformação, como laminação ou estampagem $[9,16]$. Dessa forma, buscou-se simular tal situação. Foram confeccionados doze corpos para 
realização do ensaio. As medições foram feitas com paquímetro Mitutoyo ${ }^{\circledR}$ Absolute Digimatic, para comprimento (I) e largura (w), com resolução 0,01mme micrômetro Mitutoyo ${ }^{\circledR}$ Digital para medição da espessura (t), com resolução $0,001 \mathrm{~mm}$.

Após cortados os corpos de prova receberam acabamento para retirada de rebarbas e pontas. Decorrido esse processo, descartou-se os corpos de número 07, 10 e 12. Ressalta-se que o fator de conversão de deformação cisalhante em tração é de 1,84; ou seja, deformar convencionalmente em cisalhamento implica numa deformação convencional aproximadamente $84 \%$ maior em tração.

As propriedades mecânicas do aço AISI 304 no estado como recebido foram identificadas a partir da realização de ensaios de tração uniaxial (corpos de prova de acordo com a norma internacional da Sociedade Americana de Ensaios e Materiais (American Society for Testingand Materials) - ASTM E8, taxa de deformação inicial de $0,001 \mathrm{~s}^{-1}$ e com uso de extensômetro mecânico do tipo agulhas). Os ensaios foram conduzidos em uma máquina de ensaios universais Instron ${ }^{\circledR} 5582$ com sistema de aquisição de dados Blue Hill 2. Os corpos, apresentados na Figura 1 de prova foram numerados de 01 a 09, sendo deformados (deformação efetiva) em 10\% (CP1 e CP2), 25\% (CP3 e CP4), 30\% (CP5 e CP6) e 50\% (CP8 e CP9).
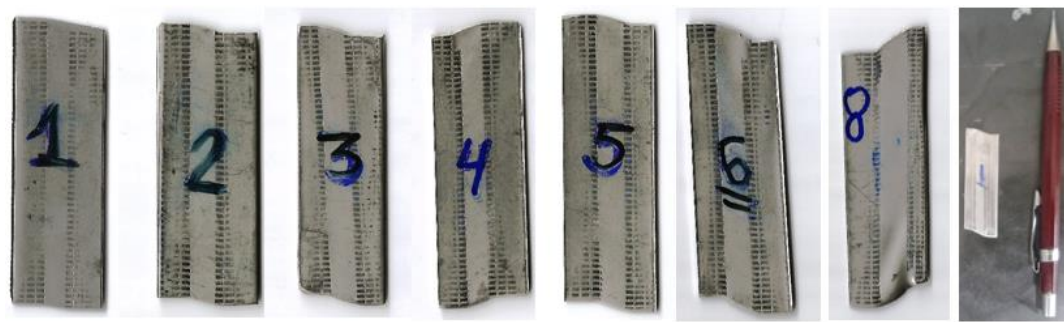

Figura 1.Corpos de prova de cisalhamento antes da imersão em solução.

Com o objetivo de avaliar a fração volumétrica de martensita formada por deformação, utilizou-se a técnica de ensaio de difração de raios-X (DRX), a qual foi realizada com auxílio do equipamento Shimadzu ${ }^{\circledR} \mathrm{XRD}-7000$, com alvo metálico de cobre, ângulo de varredura de $10^{\circ}$ a $110^{\circ} \mathrm{C}$, passo de $0,02 \mathrm{~s}^{-1}$ e velocidade de $2^{\circ} / \mathrm{min}$. Para realização do ensaio, cortou-se uma amostra de cada um dos corpos de prova de tração e de cisalhamento, na região central dos mesmos, com auxílio de máquina de corte "cut off'. A Figura 2 apresenta os equipamentos utilizados para caracterização e confecção das amostras.

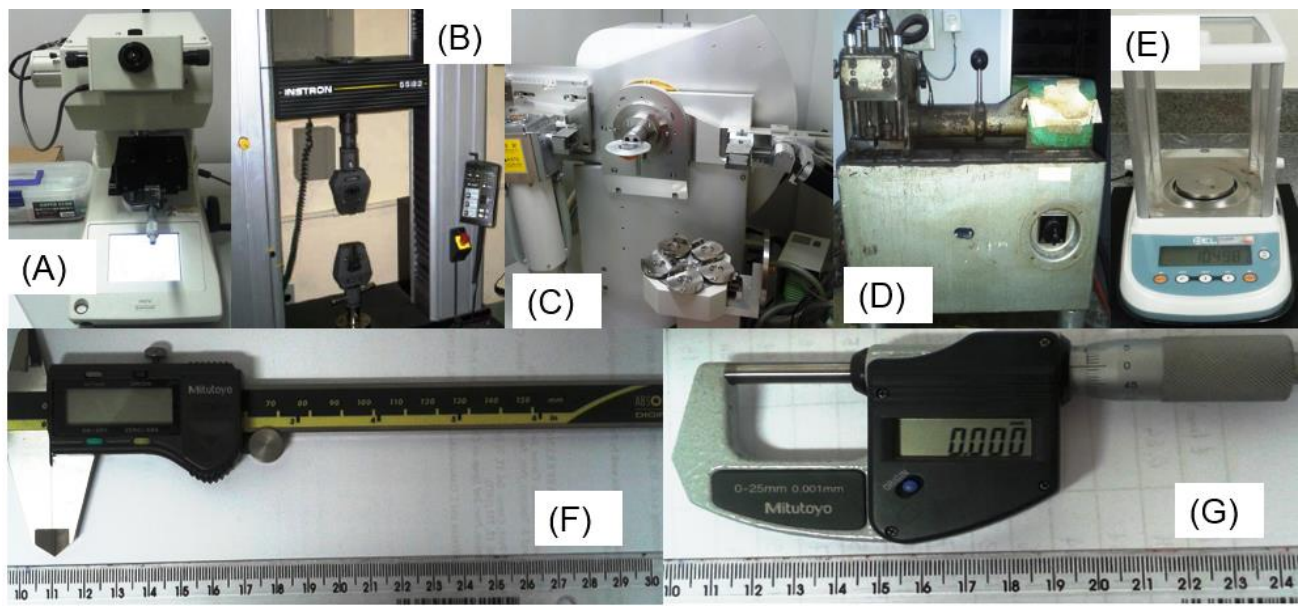

Figura 2. Equipamentos utilizados para caracterização e confecção das amostras. (A) microdurômetro, (B) máquina de ensaios universal, (C) difratômetro, (D) cut off, (E) balança de precisão, $(F)$ paquímetro e $(G)$ micrômetro. 
As amostras tiveram, no entanto, de ser decapadas para retirada dos efeitos de técnicas de processamento prévias, martensita residual e óxidos superficiais, visando minimizar interferências no ensaio. Para isso, fez-se uso de solução de ácido nítrico $\left(\mathrm{HNO}_{3}\right) 4 \%$. Os corpos de prova foram imersos em tal solução, aquecida a $50^{\circ} \mathrm{C}$, por cerca de 10 minutos, retirados e lavados com álcool etílico PA. A realização dos ensaios de corrosão é subjetiva e depende de quem os faz, não sendo os resultados e metodologia universais [1,3]. Tentou-se, no entanto, reproduzir as condições da atmosfera marinha: componente estagnado, sem muita movimentação e a temperaturas relativamente baixas (devido à profundidade das águas oceânicas). Assim, as amostras decapadas tiveram suas massas medidas com auxílio de balança de precisão BEL Engineering $\AA^{\circledR} \mathrm{M} 214$; foram imersas em solução de cloretos (água do mar artificial) e em água do mar natural, de origem de Cabo Frio.

Utilizou-se $15 \mathrm{~mL}$ de cada um dos tipos de solução supracitadas, nas quais foram imersos os corpos de prova cisalhados. Os que continham água do mar foram conservado em geladeira. Os mesmos foram colocados em solução por 58 dias. Os frascos utilizados são apresentados na Figura 3. Os frascos com tampa azul receberam a solução de cloretos e, com tampa vermelha, a água do mar natural. Os resultados do ensaio foram expressos em termos de perda de massa (corrosão) para cada uma das amostras.

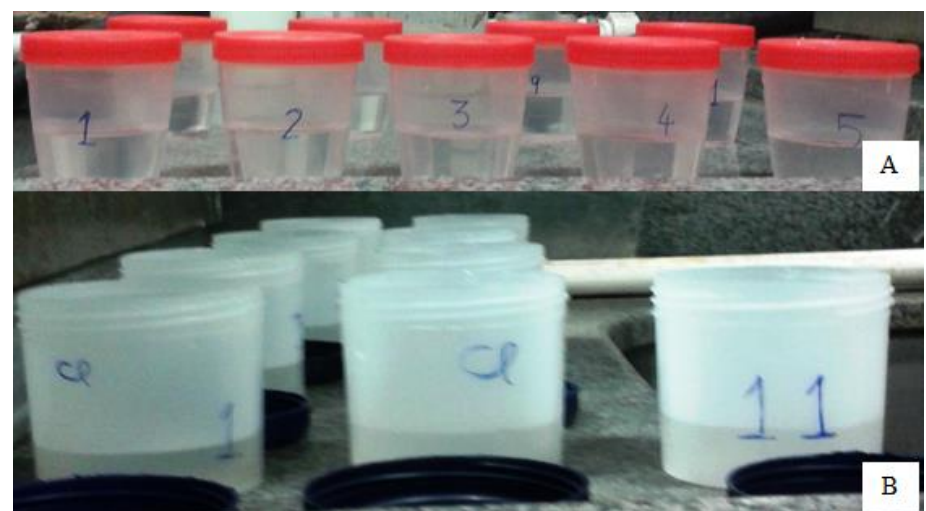

Figura 3.Frascos utilizados para ensaio de corrosão, com solução de água do mar natural (A) e artificial (B).

\section{RESULTADOS E DISCUSSÃO}

Após a realização do ensaio de cisalhamento, as amostras (depois de decapadas), foram submetidas ao ensaio de DRX para mensuração da fração volumétrica de martensita gerada por deformação. Para determinação da fração volumétrica de cada uma das fases supracitadas foi utilizada a técnica de análise semi-quantitativa (baseada na 'área' de cada um dos picos relativos às fases em estudo), com auxílio do programa OriginLab® 9.1 Pro, com base na análise de Lorentzian.

Os gráficos gerados são os denominados difratogramas. Conforme apresentado por Zandrahimi [10], o lixamento e manuseio da amostra pode gerar martensita, daí uma das justificativas da necessidade de realizar a decapagem. A fim de comprovar tal fenômeno, a amostra lixada também passou pelo ensaio de DR-X. Os resultados numéricos da análise se encontram na Tabela 1. 
Tabela 1.Análise semiquantitativa da amostra de aço AISI 304 lixada

\begin{tabular}{cc}
\hline Austenita & $52,82 \%$ \\
Martensita $\boldsymbol{\alpha}^{\prime}$ & $36,89 \%$ \\
Martensita $\boldsymbol{\varepsilon}$ & $10,29 \%$ \\
\hline
\end{tabular}

\section{Percentual aproximado das fases}

Com base em análise semelhante, acima mencionada, com os dados obtidos pelo difratograma da amostra 01 , cisalhada em $10 \%$ (deformação efetiva) foi possível gerar os resultados apresentados na Tabela 2.Com o difratograma da amostra 03, cisalhada em $25 \%$ (deformação efetiva) foram obtidos os resultados apresentados na Tabela 3.Com o difratograma da amostra 05, cisalhada em $30 \%$ (deformação efetiva) foram obtidos os resultados apresentados na Tabela 4.Com o difratograma da amostra 09, cisalhada em $50 \%$ (deformação efetiva) foram obtidos os resultados apresentados na Tabela 5.

Tabela 2.Análise semiquantitativa da amostra 1 cisalhada de $10 \%$

\begin{tabular}{cc}
\hline & Percentual aproximado das fases \\
\hline Austenita & $86,71 \%$ \\
Martensita $\boldsymbol{\alpha}^{\prime}$ & $13,29 \%$ \\
Martensita $\mathcal{\varepsilon}$ & $0,00 \%$ \\
\hline
\end{tabular}

Tabela 3.Análise semiquantitativa da amostra 3 cisalhada de $25 \%$

\begin{tabular}{cc}
\hline & Percentual aproximado das fases \\
\hline Austenita & $66,47 \%$ \\
Martensita $\boldsymbol{\alpha}^{\prime}$ & $33,53 \%$ \\
Martensita & $0,00 \%$ \\
\hline
\end{tabular}

Tabela 4.Análise semiquantitativa da amostra 5 cisalhada de $30 \%$

\begin{tabular}{c|c}
\hline \multicolumn{2}{c}{ Percentual aproximado das fases } \\
\hline Austenita & $89,34 \%$ \\
Martensita $\boldsymbol{\alpha}^{\prime}$ & $10,66 \%$ \\
Martensita $\varepsilon$ & $0,00 \%$ \\
\hline
\end{tabular}

Tabela 5.Análise semiquantitativa da amostra 9 cisalhada de 50\%

\begin{tabular}{cc}
\hline \multicolumn{2}{c}{ Percentual aproximado das fases } \\
\hline Austenita & $66,02 \%$ \\
Martensita $\boldsymbol{\alpha}^{\prime}$ & $33,98 \%$ \\
Martensita $\boldsymbol{\varepsilon}$ & $0,00 \%$ \\
\hline
\end{tabular}

As amostras imersas em solução de água do mar artificial receberam as iniciais $\mathrm{Cl}$, enquanto aquelas imersas em água do mar, a inicial M. Os gráficos acima são referentes à uma amostra de cada condição. A massa das amostras, bem como sua variação, é apresentada na Figura 4.

Percebe-se que o aumento da deformação leva a um aumento da perda de massa por corrosão, para as amostras imersas em solução de água do mar natural. Os resultados são condizentes com o apresentado por Peguet, Malki, Baroux[5], que dizem que a densidade de pites e a taxa de corrosão aumentam com o aumento do percentual de redução de área a frio [5]. 
O fenômeno notado para as amostras imersas em solução de cloretos, um aumento de massa (à exceção da amostra $\mathrm{Cl} 3$ ), embora aparentemente contraditório, é condizente com o apresentado por Torchio [2], Scoto et al [11] e Elsariti, Haftirman [12], que dizem que para tal solução, a tendência inicial é a ocorrência de precipitação de íons metálicos na superfície metálica sujeita à corrosão, seguida do surgimento das áreas anódicas e catódicas que desencadearão a corrosão e formação de pites. Porém, tal fenômeno tem duração média de 75 dias e as amostras ficaram imersas por apenas 58 dias.

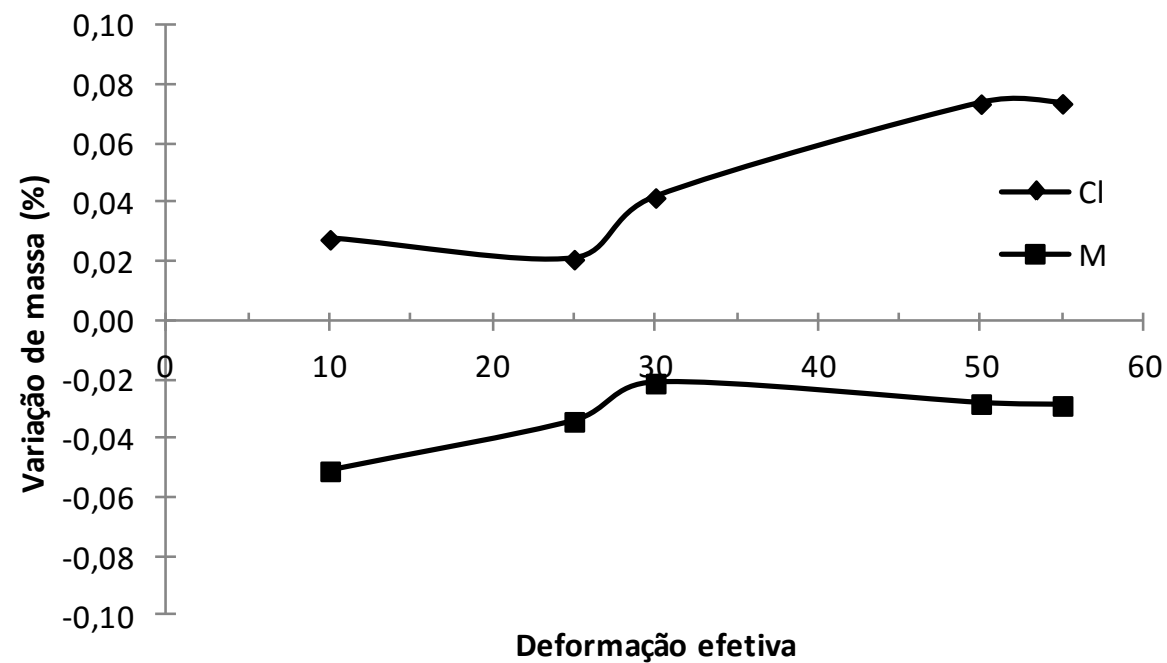

Figura 4. Variação da perda de massa (\%) em função da quantidade de pré-deformação para as amostras imersas em água do mar natural (M) e artificial (CL).

A dificuldade de realização dos ensaios, bem como a coleta adequada de resultados, deve-se ao longo período de incubação necessário e à morosidade de reprodução fiel às condições presentes na atmosfera marinha $[1,4,12]$. Mas, de forma geral, a corrosão sob tensão não depende apenas da quantidade de deformação imposta ao material, como também do meio no qual ele se encontra, conforme apresentado por Gentil [1] e Nishimuraet al [13]. Há um conjunto de condições, denominadas supercríticas, que devem ser avaliadas, segundo Desjardinset al [14] as quais foram, em parte reproduzidas, o que é notado pela concentração elevada de cloretos, segundo norma ASTM D1141/98 [3].

Fixada a condição da solução (cloretos ou água do mar), deve-se atentar para a quantidade de deformação e de martensita formada. $O$ aumento da fração volumétrica de martensita com o aumento da deformação também é condizente com o apresentado nas referências $[6,7,8,11,12]$. Porém, não há unanimidade quanto à influência dessa na resistência à corrosão do aço inoxidável AISI 304.

Peguet, Malki, Baroux [5] dizem ser a resistência à corrosão influenciada apenas pela deformação, que gera empilhamento de discordâncias e aumento da densidade das mesmas, o que gera maior diferença de potencial entre as fases e contornos de grão do material, propiciando a propagação de pites e aumento da corrosão, sendo a quantidade de martensita formada indiferente ao fenômeno.

Mas, segundo Jinlong et al[6], o aumento da fração volumétrica de martensita $\alpha^{\prime}$ gera aumento da densidade de áreas catódicas e anódicas, favorecendo a propagação de pites. Ou seja, o aumento da fração volumétrica de martensita gera diminuição da resistência à corrosão. Ainda defende que tal relação é aproximadamente linear. 
Singh [15] afirma que a textura cristalográfica e a microdureza aumentam com o aumento do trabalho a frio imposto ao material, fato esse percebido durante a realização dos ensaios de microdureza e reafirmado por Dieter [16] e Callister Júnior [17]. Dessa forma, ainda segundo Singh, a formação do filme de passivação é dificultada com o aumento do percentual de redução de área a frio, fenômeno justificado pelas evidências de Peguet, Malki, Baroux[5], mas contraditório segundo a óptica da sensitização sofrida pelo AISI 304. Dessa forma, Singh [15] afirma que para deformações de pequena magnitude, há a formação de empilhamentos de discordâncias e de bandas de cisalhamento celulares, que se sobrepõe aos demais fenômenos, sendo esse um ponto a analisar para se discutirão de martensita e da Nishimura et al [13] defendem ser a formação de martensita um fenômeno de importância fundamental na determinação da cinética de corrosão dos aços inoxidáveis austeníticos, principalmente por favorecer a ocorrência da sensitização. Tal fato é, porém, confrontado por Desjardins et al [14], que dizem ser não a sensitização, mas a corrosão por pites e suas consequências as mais determinantes para esse tipo de aço, tal qual afirmado também por Gentil [1].

Assim, os resultados encontrados podem ser discutidos por diferentes ópticas, mas condizem com 0 apresentado pelas referências, sendo a pesquisa ainda inconclusiva e em fase de realização. Deve-se trabalhar com amostras que sejam deformadas o mínimo possível (para que não haja formação de martensita) e com taxa de deformação reduzida (cerca de $10^{-4} \mathrm{~s}^{-1}$ ), a fim de se mensurar o efeito apenas da deformação na resistência à corrosão do aço inoxidável AISI 304;

\section{CONCLUSÕES}

A exposição do aço AISI 304 à ação da água do mar natural e artificial após a deformação em cisalhamento de 10\%, 25\%, 30 e $50 \%$ de deformação efetiva indicou:

- O aumento da quantidade de martensita com o acréscimo da quantidade de deformação plástica aplicada ao aço AISI 304, com exceção para a amostra prédeformada de $30 \%$ de deformação efetiva em cisalhamento, sendo isso associado ao erro na à análise semiquantitativa das fases por difração de raios$\mathrm{X}$;

- O aumento da perda de massa para as amostras mergulhadas em água do mar natural com o acréscimo da quantidade de pré-deformação em cisalhamento;

- A tendência de acréscimo da perda de massa para as amostras imersas em águas do mar artificial (solução de cloretos) durante 60 dias;

- A aparência macro e microscópica não indicaram a ocorrência de corrosão por pites ou intergranular.

\section{REFERÊNCIAS}

1. GENTIL, Vicente. Corrosão. 6. ed. Rio de Janeiro: LTC, 2011. 360 p.

2. TORCHIO, S.. Stress corrosion cracking of type AISI 304 stainless steel at room temperature: Influence of chloride content and acidity. Corrosion Science, Londres, v. 20, n. 4, p.555-561, abr. 1980. Mensal.

3. AMERICAN SOCIETY FOR TESTING AND MATERIALS. ASTM D1141-98: Standard Practice for the Preparation of Substitute Ocean Water. West Conshohocken, 2013. $5 \mathrm{p}$

4. ASM INTERNACIONAL (Estados Unidos da América). ASM Handbook 13A: Corrosion: Fundamentals, Testing and Protection. Ohio: ASM International, 2003. 23 v. 
5. PEGUET, L.; MALKI, B.; BAROUX, B. Influence of cold working on the pitting corrosion resistance of stainless steels. Corrosion Science, Londres, v. 49, n. 4, p.1933-1948, abr. 2007. Mensal.

6. JINLONG, Lv; HONGYUN, Luo. Effects of strain and strain-induced a'-martensite on passive films in AISI 304 austeniticstainlesssteel. Materials Science And Engineering C. Beijing, p. 484-490. jan. 2014.

7. PADILHA, A. F.; GUEDES, L. C.. Aços inoxidáveis austeníticos: Microestrutura e propriedades. São Paulo: Hemus, 1994. 170 p.

8. YOON, Young-sub; HEON, Young Há; TAE-HO Lee; SANGSHIK Kim. Effect of N and C on stress corrosion cracking susceptibility of austenitic Fe18Cr10Mn-based stainless steels. Corrosion Science, Londres, v. 80, n. 1, p.28-36, mar. 2014.

9. LOPES, W. Estudo do encruamento dos aços AISI 304 e AISI 409 com uso da técnica de cisalhamento planar simples. Belo Horizonte: Escola de Engenharia, Universidade Federal de Minas Gerais, 2009. 186p. (Tese, Doutorado em Engenharia Metalúrgica e de Minas).

10. ZANDRAHIMI, Morteza et al. The formation of martensite during wear of AISI 304 stainless steel. Wear. Kerman, v. 9-10, n. 263, p. 674-678. abr. 2011.

11. SCOTTO, V.; CINTIO, R. di; MARCENARO, G.. The influence of marine aerobic microbial film on stainless steel corrosion behaviour. Corrosion Science, Londres, v. 25, n. 3, p.185-194, mar. 1985. Mensal.

12. ELSARITI, Samir Milad; HAFTIRMAN, Hidrus. Behaviour of Stress Corrosion Cracking of Austenitic Stainless Steels in Sodium Chloride Solutions. Proc. Engineering. Malasya, p. 650-654. abr. 2013.

13. NISHIMURA, Rokuro; ALYOUSIF, Osama M.. Stress corrosion cracking and hydrogen embrittlement of sensitized austenitic stainless steels in boiling satured magnesium chloride solutions: Influence of chloride content and acidity. Corrosion Science, Londres, v. 50, n. 8, p.2353-2359, ago. 2008. Mensal.

14. DESJARDINS, D. et al. The correlation between mechanical and electrochemical parameters of stress corrosion. Corrosion Science, Londres, v. 20, n. 2, p.177-187, fev. 1980. Mensal.

15. SINGH, Raghuvir. Influence of cold rolling on sensitization and intergranular stress corrosion cracking of AISI 304 aged at $500^{\circ} \mathrm{C}$. Journal of Materials Processing Technology. Jamshedpur, p. 286-293. 12 set. 2008.

16. DIETER, George E.. Metalurgia Mecânica. 2. ed. Rio de Janeiro: Guanabara Dois, 1981. $660 \mathrm{p}$.

17. CALLISTER JUNIOR, William D. Ciência e Engenharia de Materiais: uma introdução. 7. ed. Rio de Janeiro: LTC, 2008. 